\title{
The Status of the Vocational Graduated Students According to Approved Targets: A Qualitative Research
}

\author{
Sajjad Sedighi ${ }^{1}$ \\ Saeid Safaei Movahhed² \\ Zahra Jahanbakhsh ${ }^{3}$ \\ 1. MA in Educational Research, direct2.2006@gmail.com \\ 2. Assistant Professor of Tehran University, s_s_movahed@yahoo.com \\ 3. MA in Educational Psychology, zjahanbaksh60@gmail.com
}

\section{Doi:10.5901/mjss.2015.v6n5s1p11}

\section{Abstract}

Due to the importance of the vocational education in the secondary education system of Iran, the present study was conducted to investigate the status of the graduated students of vocational schools from their own point of view. This study has been carried out with the qualitative approach using the case study method. The sample of this study was chosen from population of all students of the different disciplines of vocational school who were graduated about 2-5 years ago. Data collecting instruments were semi-structured interviews. Cases were interviewed and six aspects playing substantial role in the effectiveness of vocational education were detected: instruction, educational counseling, laboring, personal attitudes, social attitude, and self-confidence. Results suggest that the status of graduated students is not satisfying both in their own opinion and in comparing with the approved goals of education.

Keywords: vocational school, instruction, academic interests, social attitude, laboring, qualitative research

\section{Introduction}

Education and laboring are actively related to each other in many ways and both systems are completing. The properly simultaneous quantity and quality growth of these two types of process causes the productivity in the social system (Behbahani, 2010).

The technical and vocational instruction has an essential role in economic development of countries (Minghat \& Yasin, 2010). Considering the importance of technology development, technical and vocational instruction should be consistent with the requirements of a country (Karahuca, Dulda, Karahuca, Yucel, Gulluoglu, \& Arifoglu, 2010). The scope of work and technology in general instruction (primary and early secondary school) and the second intermediate period is the acquisition of practical skills to manage life and to gain competences required for the professional jobs in economic and social aspects of life. So the ability to achieve academic and professional abilities will cause personal development, increase productivity and participation in social and economic life, improve moral sense, reduce poverty, increase income and improvement. These trainings are to qualify human capital and assign graduated students professional jobs.

Work is more than the performance of a skill, or the provision of a technical service in return for economic rewards, but a potentially meaning-given practice in people's lives (e.g., Sullivan, 2005). Since work is not just an instrumental activity, the question of what the work we prepare people for means to them is one requiring greater attention in adult vocational education. Considering available reports, many job opportunities are not based on professional skills, so they can not deal with the new challenging fields of work and achieve the goals of development. We should specifically concentrate all our efforts on educating and technical and vocational training (The Ministry of Education, 1995).

Education systems that provide specific skills within secondary schooling and through the dual system have been found to ease entry into the labor market because of their positive influence on employment opportunities of school leavers and on the speed of the transition process. As a result, not only youth unemployment is lower in such systems, but also the quality of the initial job match is higher, as compared to countries that offer mainly general education at the upper secondary level (Gangl, 2003; Wolbers, 2003, 2007)

The results of the researches in developed countries about the relation of instruction and development implies that 
human resources have the effective role in increasing efficiency and effectiveness of economic. Enhancement of credits in education accelerates economic growth in these countries. It seems that recent advances and cooperation between the educational and economic system in these societies are resulting from the acceptance of the importance of the correlation of the learning and educating connectivity with the practical and reality fields of life and work (Azizi, 1999).

In this regard, paying attention to the role of education in promoting economic programs, particularly in terms of providing relevant and proper human resources in most third world countries, have caused numerous changes in the structure of meaning of education system. Today numerous studies on the structure of education of these countries represent the distance between the educational and economical systems. This is one of the most effective reasons causing reforms in this area to lead further reduction of the gap between them (Attarian, 2001).

For these reasons, by starting the 5-year development program in Iran since 1989 and the need of editing educational system, the vocational education established in 1992. The main component of the new system of secondary education is the technical-vocational education that formed with the aim of promoting vocational training and its most direction is the preparation of the young people for suitable works.

Therefore, educational authorities have been established the vocational education for coordinating training programs according to the students' characteristics and the needs of students and society. They believes that developing this new education coordinates training and employment more and more and finally one of the goals of socio-economic development will be achieved. Based on this reasoning, a considerable proportion of high school students are guided in different disciplines of vocational (Navidi \& Barzegar, 2004).

Purpose of vocational education in Iran is to train human resources to occupy industry, agriculture and services, based on the needs of economic, social, and cultural development of the country. So that every one of applicants for jobs achieves the required knowledge and sufficient skills for the job that they are doing or are to do.

In order to provide the necessary conditions for the implementation of vocational training in the new system of education, its definition, objectives, curriculum principles, organization and executive policy of these instructions were approved by the Supreme Council of the Cultural Revolution:

Article 1 - the vocational education refers to the instruction that promotes the knowledge and skills of individuals and actualizes their latent necessary talents to prepare them to achieve jobs, professional businesses and to increase their ability for getting jobs they have been assigned.

Article 2 - the vocational education is one branch of the secondary educational system that is designed based on the general targets and governing principles toward this organization.

Article 3 - Purpose of the vocational education is instructing human capital needed for industry, agriculture and services, based on the economic development, social and cultural needs of the country So that anyone of instructed persons or applicants for jobs reach the related knowledge and sufficient skills for their field.

Article 4 - The goals of the vocational education in the secondary system also involve the general goals of secondary education which are included of:

1. Learning the techniques and skills which are needed by society.

2. Guiding and developing the talents of individuals related to their interest and motivations they have for their fields, professions and careers and developing the ability of choosing career and finding the right way to live according to goals of individuals and society.

3. Developing the spirit of confidence in individuals by achieving the certain abilities

4. Fostering the spirit of discipline and planning in personal and social affairs

5. Strengthening curiosity

6. The extension of knowledge and intellectual abilities, practical and technical understanding of the role of science and technology in the development of individuals and societies

7. Understanding the importance of handicrafts and the importance of jobs in making an independent economic.

8. Development of studying ability, communication and self-educating ability (The Ministry of Education, 1995).

School-to-work-transition is a complex process that is reflexively constituted by integrating individual agency with the opportunity structures in which young people find themselves in under conditions of increasing transition discontinuities, contingency and unpredictability (Vogtenhuber, 2014). The success of vocational instruction in educating skilled and powerful labor force has been discussed in several studies and there are contradicting official reports on how successful technical and vocational programs are. Some of them evaluated that it is quite successful practice in some respects . However, there are evidences that show there are weaknesses and shortcomings in technical and vocational programs.

High costs and uncertainty about the vocational graduated students' appointment to the jobs are the important issues affecting the process of making decision about educating in a vocational school. Whilst some studies regard job 
mismatches amongst labour market entrants as a temporary phenomenon that diminishes over time after accumulating work experience and job-related skills (for a review see Quintini, 2011), a considerable body of evidence points to the long-term negative effects of a mismatched labour market entry (Brunner \& Kuhn, 2010; Genda, Kondo, \& Ohta, 2010; Vogtenhuber, 2014; Kahn, 2010; Oreopoulos, von Wachter, \& Heisz, 2012).

What makes this research different from other studies is that the present study investigates the status of programs and curriculum from graduates' own point of views as the educated of this curriculum. The aim of our study was to investigate the causes of the failure at the technical and vocational field from the perspective of graduates of its branches, to get a better and clearer picture of the current state of them.

Comparative research on country variation in youth labor market integration has increasingly paid attention to the structure of the education, training system, and more specifically to the extent to which vocational specific skills and qualifications are provided within upper secondary schooling. Many studies found that young people in countries with strong initial vocational education and training (VET) systems fare better than their counterparts in countries that provide mainly general education (e.g.; Brzinsky-Fay, 2007; De Graaf \& van Zenderen, 2013; Scherer, 2005; Wolbers, 2007).

In developed countries, there is very close relationship between schools and real environments of work. Students with an understanding of the facts about businesses are training to meet the expectations of enterprises. Such an efficient pattern of secondary education in technical and vocational fields can be observed in most of the European countries especially Germany, Sweden, Denmark (Azizi \& Lasonen,2006).

Despite the heavy costs that spent on technical and professional instruction programs in Iran, the research evidence suggests that some technical and professional graduates are unemployed while many workers who are found the way to work opportunities are unskilled in the initial stages. There are also many technical and professional graduates (60\%) were not employed in jobs related to their field of study (Navidi, Ghasemi, Marjani, \& Derakhshan,2004).

Inspite of more than 25 years of planning, the education system in vocational training in Iran have no comprehensive program to connect the education of human resources to professional labor market. So, most of our educational efforts are quantitative and not qualitative. A simple comparison between Iran and some developed countries such as Germany, India, Japan and Russia reveals that the countries with exact and powerful system of technical and vocational education have greater prosperity and welfare. This fact demonstrates low quality of technical and vocational education in Iran (Behbahani ,2010).

Technical and professional education can be one of the important ways to obviate the lack of appropriate development and to reduce poverty (Pavlova, Chunlin, \& Huang, 2009).

Youth unemployment in OECD countries has consistently remained around twice the rate of that in the workingage population as a whole over the last two decades. In 2010, 18\% of 15-29 year olds who had left school in the OECD area were unemployed, compared to $10 \%$ for the working age population as a whole (OECD, 2010a). To deal with youth unemployment, governments around the world have focussed on improving engagement in education, especially for students at risk of dropping out of school and becoming long-term unemployed In English-speaking countries where the focus is on general upper-secondary education, a key measure to improve engagement in school has been to integrate vocational education and training (VET) courses into the upper-secondary school curriculum(Polidano, Tabasso, 2014).

Based on findings of research in Iran it can be deduced that studying in the vocational fields of education cannot increase the chances of professional employment. Navidi \& Barzegar (2004) showed that Over $25 \%$ of men and $52 \%$ of women, who were graduated at least two years ago, are unemployed. On the other hand, $30 \%$ of men and $20 \%$ of women have been successful to obtain suitable job and the rest of them are unemployed, are studying, or are called up for military service. Based on statistical estimates about $30 \%$ of men and $60 \%$ of women are unemployed and over $50 \%$ of people find jobs that do not match their professional education (Navidi \& Barzegar, 2004).

Navidi and Barzegar (2004) reported that, based on the judgment of scholars, totally $16 \%$ of employed graduates of vocational courses such as mapping and accounting who were graduated before 2001, are employed in jobs that are reasonably related to their field of study ( $29 \%$ of women and $9 \%$ of men). It is expected that between $11-21 \%$ of employed people could find jobs that are reasonably related to their field of study. They also reported that the rate of unemployment is $45 \%$ in these two fields. According to the Statistical Center of Iran, the rate of unemployment for people who was 18-24 year old was $27 \%$, which suggests that the vocational education cannot increase their chances of getting suitable jobs.

Shariat Zadeh (2009) in the investigation of male graduates of agriculture in vocational schools found that about $\% 5 / 6$ of graduates were working and $57 \%$ of them are unemployed after completing military service. Employment of graduates does not seem satisfying compared with their peers holding diploma and college degree in the age group of 24-20 years.

Lorestani (2002) reported that, due to the lack of jobs, approximately $3 / 54 \%$ of individuals did not get jobs fitted 
with their fields.

Korpi, De graaf, Hendrickx, and Layte (2003) indicated the strong association between educational qualifications and subsequent labour market attainment, as well as from the ongoing lively debate in many countries about the design of the educational system. Their results showed substantial differences in employment precariousness among graduates in Great Britain, the Netherlands and Sweden. They suggested that precariousness is generally inversely related to educational attainment. This is the case for both the risk of unemployment as well as the risk of becoming long-term unemployed and, to some extent also, for the school-to-work transition. In contrast, the results from the analyses suggest that the impact of vocational training on labour market precariousness varies over the work career. The basic hypothesis in this article has been that a greater degree of specific training would be advantageous at the initial stage of a career, as it would give a clear indication of skills when other information was lacking. However, in later stages more general training would indicate a greater potential for skill acquisition.

Investigating the employment status of vocational and technical graduates in the science of computer and electronics in Tehran, Barzegar (2002) showed that $24 \%$ were employed, $40 \%$ were unemployed and $28 \%$ were students and $8 \%$ of them were doing their military service. Also Panahi (2000) reported that $21 \%$ of vocational graduates in the city of Ardabil were employed and $74 \%$ of them were not. furthermore $14 \%$ of employed women and $35 \%$ of men who were employed founded a proper job related to their field. Hasanpour (2002) also reported that the rate of employment of vocational graduates in Ardabil is 9.3\%.

Entrepreneurship education has developed rapidly during the last two decades. The need for entrepreneurship education stems from the overarching shift in the job market during the $21^{\text {st }}$ century; a shift that has meant that new skills, capabilities for reorientation, multiple careers, and active engagement in one's own success are now required (Ruskovaara, pihkala, Seikkula-Leino, Riikka jarvinen, 2015). In other words, the current working environment calls for an entrepreneurial mindset for everyone. To meet these expectations, the development of curricula, pedagogical approaches, and rich content regarding entrepreneurship have been considerably targeted (see European Commission, 2013). There is some evidence that graduates do not handle professional jobs skilful after vocational training courses (Besharati, 1996; Qurban Husseini, 1995; Khani, 2001; Salehi, 2006; Salehi, Zeinabadi, \&Parand, 2009). Analyzing the content of interviews with female graduates of vocational schools in Tehran, Salehi, Zain Abadi and Parand (2009) showed that during their studying, they could not receive appropriate training for entrepreneurship which is one of the major goals of vocational schools.

Salehi, Zein Abadi, \& Kiyamanesh (2007) proposed that knowledge, skillfulness and creativity are at the low level in vocational graduates in Tehran.

According to these contradicting events the main goals of this research were:

- To investigate the status of vocational fields from graduates' point of view.

- To compare the current situation with approved goals of the vocational education.

\section{Method}

\subsection{Participants}

Participants were 7 male students who were graduated in a variety of fields of the technical and vocational education from school $X$ between $2-5$ years ago.

\subsection{Data collection and analysis method}

This research is based on qualitative approach which was conducted by using case analysis methods. As defined, "the qualitative approach is an attempt to describe social opportunities, events and small groups according to detail. This method is trying to provide an interpretation of meanings that human beings give to their lives in normal situations. It is assumed that social interaction provides an overview of interlocking relationships that can be inductively perceived" (Mohammadi, 2011, p.16). "Case studies include the systematic collection of information about individuals and social situation, event, and groups which allow the Researcher to effectively perceive how these elements function" (Rheinhars, 1992, quoted by Safiri 2008, p. 250). Although the case is referred to a group of people who have common cultural elements, but in practice, case studies deeply investigate a trend, an event, a program or an activity" (Miller \& Salkind, 2002, quoted by Mohammadi, 2011, p. 94).

In our opinion, the representation of the vocational training curriculum from the graduates point of view draws clearer and more realistic picture of the current situation through the validity data. 
The data needed for this research were collected using semi-structured interviews. The interviews took place where participants felt comfortable (e.g. park, home, work, etc.). Interviews recorded by permission of graduates. In this research all participants were given the nicknames.

The duration of interviews was from 20 to 60 minutes. However, we spent considerable time before and after each interview to establish a more intimate relationship talking about their daily routine. After writing interviews on a paper, the process of coding was done in two steps:

- Open coding: (include of reading the data line by line, extracting key concepts and words, forming categories and classes)

- Axial coding: (include of classifying the data, identifying sub-classes, forming final classes).

We used multilateral review to ensure the reliability of the research. In order to investigating the reliability of our study, a wide range of sources were used and they discussed about analysis by the use of them. The interviews were continued until they reached the saturated point. The methods of sampling were convenient sampling and targeted sampling. In the targeted sampling method the researcher is to understand the experiences of all participants in the study (Haj Bagheri, 2007).

\section{Findings}

Analyzing the interviews with the graduates of vocational schools, findings is classified into 6 main categories and 15 subcategories:

\section{Instruction}

\subsection{The efficiency of teachers}

The presence of skilled teachers in the educational system plays a substantial role in the education process. Ali -one of the participants- said, "Teachers did their best, they were responsible and were not negligent ..."

It seems that graduates satisfaction of professional courses' teachers has effect on their motivation. Hassan another participant- said "(teachers) of professional courses were extremely good, he was not negligent. If he did not know, he would ask.... ". Boiouck was also emphasized on these opinions.

\subsection{Methods of teaching}

Today the active learning methods are emphasized. These methods shift the status of the students from passive to active. Hassan mentioned that "teachers can teach the ability of analysis easily. I think the foundation of system of education is weak. For example, only one person could be innovative among 1000 person every year. For example about a mathematical function, one day they teach $\mathrm{X}$ is like this ... and another day they teach $\mathrm{Y}$ is like this. They give us the answers, but I think they should change the function..."

Saeed said that "If we were asking any question, our teachers would answer. But they didn't explain more than defined programs themselves."

\subsection{The absence of up-to-date educational equipment}

In order to effective education efficient and up-to-date educational tools are required. Ehsan said "for example, electrical panel, which we made in school, were not practical when I compared to my brother's artifact". He insisted "Moreover, they did not teach us anything. The best skill we learned was closing star-triangle transform, which is done automatically, and there is no need for cabling and such actions".

Even the issue of education during educating overshadowed the instruction and led to lower level of motivation in teachers and students, and the instructions could have poor quality. Sajjad and Adib was agreed that "The systems in our school were not good. There were errors in systems or contained viruses ... I think it was not satisfying really, but I say they trained us well without enough facilities."

If services including training and equipments is out of date, creativity which is serious and important component will affect. Hassan explained, "For instance, teachers were talking about carburetors, while all machines have the system of injectors. We talk about antiquated systems, so the students will be innovative no longer". 


\section{Individual Attitudes}

\subsection{Giving preference to technical fields rather than theoretical fields}

Learning a particular skill in the vocational fields and making students feel empowered, are causing relatively satisfaction among vocational students. Sajjad said, "... you see, it was better for me to study IT or Information Technology. Of course I was content with my vocational school. In my opinion it was much better than the theoretical fields. It was really good for me".

Interestingly, the vocational graduates compare their diploma with theoretical fields' diploma and feel confident of their capabilities. Ali said, "In my opinion, the computer field would be better for the job. For example, suppose you study hardly in Humanities or Science to get a job, but it is not very likely to get it. In computer fields you can find a job but in other fields it is difficult to find ..."

\subsection{To have an interest in the field of education}

To have an interest in the field of education is one of the important components of learning and it could actuate people toward predicted goals. Hassan said "I failed seven of my courses in the first year of high school ... I lately enrolled on the vocational school because I was interested in the mechanic of car field, all schools were filled and they did not enroll me. My brother suggested enrolling on Mathematics. Finally I went to the vocational school X and I was the top student in the second year of the high school". Ali also said," At that time, I was interested in programming because programming was a good new major ..."

Again, Boiouck mentioned, "I was so interested in my field that in addition to the vocational school I went to the vocational professional office and enrolled on the courses.

\subsection{The application of skills in the life}

It is clear that after the end of the course, graduates have learned skills that can be used in personal life. This is one of points that they mentioned. Ehsan said, "...Yes, I fix my appliances by myself. I open it and check whether one of pieces should be repaired. Then I can repair it." Some graduates believed that they can use their skills in their lives to some extent. We Asked Sajad: "Do you lose the opportunity to use your skill if you employ in an administrative job?" In response to our question he answered "We need to work with computers even in administrative jobs". Although Adib worked in his father's facilities shop, he said, "I apply skills which I learned in my work."

\section{Social Attitudes}

\subsection{The negative attitude of the Educational system toward vocational education}

It seems that the style of behaving toward vocational graduates causes negative motivations in them. Hassan regarded this issue as a problem and said "They expect us not to continue education after graduating from high school. Students encountered a number of difficulties if they want to continue... We were considered as an educated worker. It is a problematic issue".

Saeed asserted about the importance of the vocational issues to the educational system that "you know better; they did not care about the technical vocational fields."

This problem is so important that Hassan said, "They treated us as we were addicts!!!..."and" ... overall, the vocational education was not considered an important field technically ..."

\subsection{Considering vocational graduates as proletarian}

Unfortunately because proletarian are low-ranking members of society, it increases negative attitudes of graduates. Hassan said "most people do not consider us as scholars. They consider us an educated proletarian. I have a serious problem with this issue". This is big foible in vocational fields". 


\section{Self Confidence}

\section{1 low number of successful role model students}

To have unemployed friends, not having successful models in the field of entrepreneurship, observing classmates who are either unemployed or working on the jobs irrelevant to their fields, and not finding a suitable job cause reduction in graduates' self-confidence and their motivations to continue working and post-secondary education. Ali said, "I have a friend who holds a B.S. degree in the field of computer, but he is a Taxi driver now." Although he acknowledged the existence of some jobs, he said, "There are works with a low salary." Ehsan explained about the status of his classmates "about the rest of my classmates (except Mr. X who is a refrigerator repairer) that I am in touch with them, one of them had studied ranching like me, one of them is trying to pass the university entrance exam, and the other is a car mechanic along with his father ... ". Saeed said," ... Yeah, The problem was continuing education. Diploma of PLC did not work. "Hassan, Adib and Buick also emphasized on this issue with similar expressions. They asserted that they have not ran into any of their classmates that got a job in connection with their fields.

\subsection{Lack of Interest in Entrepreneurship}

One of the goals of the vocational fields is making professional job opportunities, so graduates can makes money by standing on their own feet. Hence, Entrepreneurship is one of the courses of technical-vocational fields. However, Sajjad says: "But I like to be a government employee. It is more satisfying than being an entrepreneur."

Relying on the interviews, we found that many graduates of vocational fields do not seriously follow entrepreneurship or finding suitable jobs in their field. Saeed stated "I did not looking for a job. I was thinking of continuing education." We asked Ehsan if he has taken out a loan with his technical-vocational degree. He replied," I did not follow it .Even I did not think about taking out the loan"

\section{Counseling}

\subsection{Absence of educational counselor in educational guidance}

The educational guidance has an important role in talent searching and planning for the future of students. Therefore neglecting the educational guidance can cause damages that nothing can compensate for it. We asked Saeed whether he had an educational counselor in first year of high school or not. He answered "Yes, we had. But our educational counselor did not work properly, one day he did not have enough time and another day he was off"

\subsection{Few number of Advisors in comparison with the number of students}

In the educational system the shortage of advisors in comparison with the number of students is a serious problem that its destructive effects will be shown on the student's life. About the shortage of advisors Saeed said, "I did not remember that the counseling time was Saturday or Monday. suppose that about 500-600 number of people want to ask a counselor for advice all through two days about 12 hours". This fact has even bad effects on the student's fields selection. Saeed asserted that he was following his favorite field "computer", but the deputy head of his school led him to another field. He siad, "Well, the deputy head of school told me to choose PLC. You know, it is one kind of a computer fields which is related to system hardware". 


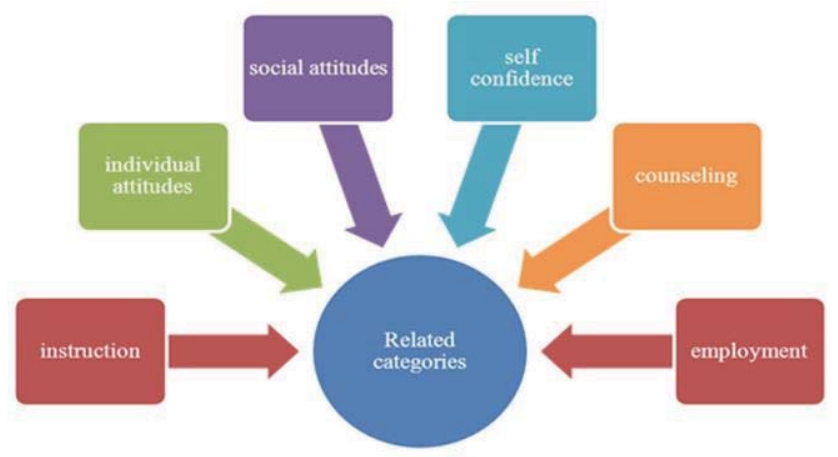

Figure 1. The categories obtained from the interviews with vocational graduates about their status

\section{Employment}

\subsection{No support for the business}

In order to leading the vocational graduates to entrepreneurship and self-employment, stimuli should be designed. Ali said "in my opinion, they should give those who are the first, second, and third grade of their fields a loan. At least they should loan them 2-3 million tomans to start a professional job."

There are some difficult conditions for receiving self-employment grant. These conditions slow applying graduates' skills in the society down. The goals of vocational education can be overshadowed by financial difficulties. Ali stated, "They grant us a loan, but first you should develop a work. It means that you should open a shop, employ at least two people, pay them and insure them and ..."

Ehsan had changed his field in higher education. Although he tried taking out a loan for his field, he did not succeed. He said, "I proceeded to keep poultry. We prepared everything like the farmland, instruments, and etc. Then we got the business license, but they simply told us that they do not give loans anymore ...". We asked Hassan whether a person can work with the vocational diploma or not. He answered, "It demands considerable investments". Saeed answered to this question in a similar way.

Buick expressed that he was intended doing a work related to his degree, but he opened a shop to sell nuts because the market was in bad conditions.

\subsection{The Lack of Employment in Governmental Organizations for vocational graduates}

Although employment in the governmental organizations is not the only indicator of the market's status, failing to employ in governmental organizations caused reduction in graduates' motivation for finding jobs and continuing education related to their field. Sajad said, "... But I am interested in governmental jobs. I want to be a government employee. it was more satisfying for me than entrepreneurship works".

\subsection{Getting the equivalent license from other organization spending less time}

The instructions provided in the vocational schools are skill-based ones. Actually, the process of education is based on the standards defined by the organization of vocational education. The process of education in this organization is differed from other organization in that the period of educating is shorter. Ali said "I know a person who has gone to the technical-vocational center in Meriyanaj city for 3 months and to get the license which is as equal as our license. But surprisingly our license is worthless in comparison with his license..."

\section{Discussion and Conclusion}

This study was aimed to investigate the situation of the vocational education and compare it with the goals of educational system. It must be emphasized that the research findings are based on data from the case study, so it is not a 
comprehensive study. But we can claim that this research has investigated many issues deeply because of its method.

Training a work force qualified enough to meet the expectations of the business world should be the priority of educational institutions. Especially, the institutions providing education in vocational and technical field to train personnel for intermediate level should continuously revise and develop their curriculums. Moreover, Vocational High Schools should update the content of education provided within the criteria of expectations and training individuals who have flexible skills.

As was mentioned earlier, officials and politicians in the educational system established the field of the vocational education to coordinate educational programs, students' characteristics and requirements of society. They believe that by making this decision the educational system dovetail with the employment. Therefore one of the goals of socio-economic development will be fulfilled (Navidi \& Barzegar, 2004).

Unfortunately, the traditional view of teaching can reduce the curiosity and creativity. Remy and Piper (1974), Sullivan (1974) compared the dynamic or open classrooms with traditional ones. Results showed that the space of dynamic or open classrooms was appropriate for developing the research situations, curiosity, manipulation, and selfdirected learning. The weakness in these components gets the teacher into trouble and make the graduates think that they are deficient through the years of education and after graduation. Ali said "In my opinion, our courses were theorybased. We just did the instruction written in our books. There was no project which allows us to work creatively and progress ... our computer courses were boring".

Although learning a skill reinforces curiosity, the method of teaching has a great influence on it. Hassan stated "it was better if the equipments were modern. We learned to repair machines, but we did not learn to analyze them. For example, we could explore where the better choice for placing a screw is". The findings of this study consistent with the paragraph 8 of the act 4, passed by the ministry of education, referring to develop the ability of studying, communicating, and self-educating show that continuing education can realize these abilities. We asked Ali whether he can do the programming or not. He responded, "Not now... I have not worked with the computer for a long time, so I cannot work with the system of Windows a skilful as the past". Hassan, who has continued his education, approved that his abilities have been developed. However, Brown and House (2004, quoted by Salehi, Zain Abadi, \& Kiamanesh (2007)) believe that increasing the capacity of universities cannot be a good alternative when there is a want of technical and professional skills.

Our results about employment and finding suitable jobs are consistent with Korpi et al (2003). According to act 1 , passed by the ministry of education, instruction should prepare a person for achieving specific jobs and careers. However, the lack of new and modern equipments and the absence of educational counselor have disrupted achieving this goal. Hassan asserted, "We study out of date lessons. For example our lessons are about carburetors while all cars have injectors today". Saeed was emphasized on the absence of educational counselor too. Couple of research were conducted to investigate the effects of counseling and psychotherapy to individuals' adjustment problems. The results of studies, conducted to investigate the effects of counseling, indicate that it can moderate problems. Also participants acknowledged these positive effects (Fazeli, 2002; Ya'ghoubi, 1996).

So until the basic needs are not satisfied, graduates cannot reach enough technical skills which are needed to do professional works. As a result, it is not possible to educate students concerning economic, social, and cultural needs of the society. Navidi and Barzegar (2004) carried out the study to investigate the status of the employment and vocational skills in graduates of computer and electronics fields. They concluded that the vocational education and students' skills are not sufficient to perform job duties and achieve success.

Although the education system is satisfying the needs of the business market through training human resources, the emergence of increasing developments in the science and technology have changed the needs of human resources (Lindbeck \& Snower, 2000).

As the participants mentioned, lack of support for entrepreneurship and self-employment and some of complicated work laws make the problems worse. Ali said, "I think graduates are faced with financial problems. If they had been protected, they would have been hopeful". Schools should encourage students who have entrepreneurial skills. As a result, we will have graduates who can initiate new work rather than seeking jobs irrelevant to their professions (Salazar(1986, Translation of Nateghi,2007)). Saeed mentioned, "Decision makers who established vocational education should also pay attention to their employment."

It seems that the existing conditions of vocational education are in contradiction to 'Article 3' - Purpose of the vocational education is instructing human capital needed for industry, agriculture and services, based on the economic development, social and cultural needs of the country So that anyone of instructed persons or applicants for jobs reach the related knowledge and sufficient skills for their field.

Fostering self-confidence appears in students through achieving particular abilities. The process of learning skills 
itself can result in self-confidence. For example Ehsan said, "My brother is a builder. When he works on a building project, I can help". Unfortunately, the lack of modern equipments, employment status of other graduates, the lack of individual facilities and lack of supporting for finding jobs, and considering vocational graduates as labors lead to low selfconfidence in the graduates. There is some evidence of the weakness of vocational graduates in performing job duties after completion of skills training courses (Besharati, 1996; Qurban Hosseini, 1995; Khani, 2001; Salehi, 2005 ; Salehi et al. 2009). Although Buick had professional job opportunities, he is working in an administrative job.

Improvements within a technical-vocational education and training (TVET) system can be carried out in terms of a particular element of the system, such as qualification standards and specialization; articulation with general education; assessment and certification for achievements; methods of curriculum development; governance; labor-market analysis; financing; legislation; access and admission; provision of training places; special target groups; institutional arrangements for delivery; and, information and guidance. TVET is situated at the border between education and work. TVET policy should be closely linked with other policy areas and institutions, in particular to those dealing with education, work, employment, and economic development. Therefore, for the policy formulation, the specific context of a particular country should be taken into account to identify an adequate response to immediate and future labor-market needs (Maclean, Pavlova 2010).

In conclusion, it can be noted that the main goals of the vocational education have not been properly fulfilled. In some fields, which there are some success points, we should study the relation between the costs and time and the output. It is important not to ignore the problems such as unemployment and economic problems.

\section{Suggestions}

- The structural review of the vocational education from the perspective of teachers in order to demystify problems

- Selecting teachers characterized by creativity and good intuition in noticing bonds between knowledge, technology and demands of the labour market.

- The review of the educational status of vocational schools' entrants in order to analyze vocational education accurately,

- Investigating the social and cultural status of the vocational students' families in order to provide a clearer perception of the educational status of students, their future, and etc,

- To modify educational counseling procedures as one of the important factors in the educational system,

- To localize the curriculum for vocational education.

\section{Refrences}

Attarian, N. (2001). Review the situation and factors associated with the employment of graduates of technical of Khorasan province and Mashhad. Research project. Khorasan: Organization of education in Khorasan.

Azizi, N. (1999).The article introduces the relationship between education and economic development: the need for methods and new approaches connecting the education system to the labor market. Journal of Education, 55\&56, 39-58.

Azizi, N., and lasonen, J.(2006). Education and Training and the Economy: Preparing Young People for a Changing Labour Market. International Institute for Educational Research: Jyvaskyla University Press.

Barzegar, M. (2002). Employment status of graduates skilled in computer and electronics branch in Tehran Kardanesh. Research projects. Tehran: Education Organization in Tehran.

Behbahani, A. (2010). Technical and vocational education and the structure of education system in Iran. Procedia Social and Behavioral Science 5, 1071-1075.

Besharati, M. (1996). Evaluation of the failure of the new system of secondary education in the field of Kardansh students, educators and high school students under this system. Master's thesis. Tehran: Allameh Tabatabaii University, Faculty of Education.

Brzinsky-Fay, C. (2007).Lost in transition? Labor market entry sequences of school leavers in Europe. European Sociological Review, 23(4), 409-422.

Brunner, B., \& Kuhn, A. (2010).The impact of labor market entry conditions on initial job assignment, human capital accumulation, and wages. IEW working paper, 520.

Dahar, M., and Ruhizan M.Y. (2010). A sustainable frame work for technical and vocational education in Malaysia. Procedia Social and Behavioral Science, 9, 1233-1237.

De Graaf, W., \& van Zenderen, K. (2013).School-work transition: The interplay between institutional and individual processes. Journal of Education and Work, 26(2), 121-142.

European Commission. (2013). Entrepreneurship 2020 action plan. Reigniting the entrepreneurial spirit in Europe. Communication from the Commission to the European Parliament, the Council, the European Economic and Social Committee and the Committee of 
the Regions. Retrieved from http://eur-lex.europa.eu/ LexUriServ/LexUriServ.do?uri=COM:2012:0795:FIN: EN:PDF.

Gangl, M. (2003).The only way is up? Employment protection and job mobility among recent entrants to European labor markets. European Sociological Review, 19(5), 429-449.

Genda, Y., Kondo, A., \& Ohta, S. (2010).Long-term effects of a recession at labor market entry in Japan and the United States. The Journal of Human Resources, 45(1), 157-196.

Fazeli, A. (2002). Current status of counseling centers and counseling impact on academic achievement. Research projects. Tehran: Institute of Research and Planning in Higher Education.

Haj bagheri, A. (2007). Grounded Theory research methods. Tehran. Boshra.

Hasan Poor, H. (2002). Examine the place of employment of graduates of technical and vocational fields Kardansh Ardebil province. Ardabil: Education Organization.

Kahn, L. B. (2010).The long-term labor market consequences of graduating from college in a bad economy. Labor Economics, 17,303316.

Karahuca, D., Dulda, I. Karahuca, A.Yucel, A., Gulluoglu, B., and Arifoglu, E. (2010). Interactive e-content development for vocational and technical education. Procedia Social and Behavioral Science, 5842-5849.

Khani, A. (2001). Factors associated with the employment of graduates' employment status Kardansh Khorasan branch. Research projects. Mashhad: Education Organization.

Korpi T., de Graaf T., Hendrickx, J. and Layte, R. (2003) Vocational Training and Career Employment Precariousness in Grear Britain, The Netherlands and Sweden, Acta Sociologica 46(1), 17-30.

Lindbeck, A., and Snower, D. (2000). Multi task learning and reorganization of work: from Tayloristic to holistic organization. Journal of Labor Economics, 18(3), 67-353.

Maclean R., Pavlova M. (2010). Planning and Policy Development for Technical Vocational Education and Training Systems In Peterson p., Baker E., McGaw B. (2010) International Encyclopedia of Education (469-475) United Kingdom: Elsevier.

Marashi, S.M.(1993). The role of educational technology in teaching geography. Growth Teaching geography,36,26-30.

Milto, Salazar. (1998). Introduction to Entrepreneurship. (N. Siamak, Trans). Tehran: National Productivity Organization of Iran.

Mohammadi, B. (2011). Introduction to qualitative research method. Tehran: Institute for Humanities and Cultural Studies.

Navidi, A. Barzegar, M. (2004). Employment status of graduates Accounting and Construction Drawing. Journal of Education, 77, 113152.

Navidi, Ghasemi, Marjani, Derakhshan. (2004). Review of Vocational Education Research. Tehran: Ministry of Education, Institute of Education.

OECD (2010a). Off to a Good Start? Jobs for Youth. Paris: OECD.

Oreopoulos, P., von Wachter, T., \& Heisz, A. (2012).The short- and long-term career effects of graduating in a recession. American Economic Journal: Applied Economics, 4(1), 1-29

Polidano C., Tabasso D. (2014). The benefits of workplace learning in upper-secondary vocational education and training courses. Economics of Education Review 42, 130-146.

Quintini, G. (2011).Over-qualified or under-skilled: A review of existing literature, OECD social, employment and migration. Working papers no. 121. OECD Publishing.

Ruskovaara E., Pihkala T., Seikkula-Leino J., Riikka Jarvinen M. (2015) Broadening the resource base for entrepreneurship education through teachers' networking activities. Teaching and Teacher Education, 47, 62-70.

Sullivan, W. M. (2005). Work and integrity: The crisis and promise of professionalism in America(2nd ed.). San Francisco, CA: Jossey Bass.

Vogtenhuber, S. (2014). The impact of within country heterogeneity in vocational specificity on initial job matches and job status. Journal of Vocational Behavior, 85, 374-384.

Wolbers, M. H. (2003). Job mismatches and their labor-market effects among school-leavers in Europe.European Sociological Review, 19(3), 249-266.

Wolbers, M. H. (2007).Patterns of labor market entry a comparative perspective on school-to-work transitions in 11 European countries. Acta Sociologica, 50(3), 189-210. 